ORIGINAL ARTICLE

\title{
Reducing medication errors in the neonatal intensive care unit
}

\author{
J H Simpson, R Lynch, J Grant, L Alroomi
}

Arch Dis Child Fetal Neonatal Ed 2004;89:F480-F482. doi: 10.1136/adc.2003.044438

See end of article for authors' affiliations .....................

Correspondence to: Dr Simpson, Paediatric Department, Princess Royal Maternity Hospital, 16 Alexandra Parade, Glasgow G31 2ER, Scotland, UK; judsimpson@hotmail.com

Accepted 10 March 2004
Background: Medication errors are common in the neonatal intensive care unit (NICU). Various strategies to reduce errors have been described in adult and paediatric patients but there are few published data on their effect in the NICU.

Aim: To describe the medication errors occurring within an NICU, and assess the impact of a combined risk management/clinical pharmacist led education programme on these errors.

Methods: Medication errors were identified prospectively over one year by critical incident reporting. Four months into the study, a pharmacist led education programme was instituted. This involved a daily, cot side, pharmacist led review of medication orders. Each new member of pharmacy, nursing, or medical staff was also required to successfully complete a series of dose calculations. In addition, a risk management approach was used to make several changes in practice during the study period.

Results: A total of 105 errors were identified, four serious, 45 potentially serious, and 56 minor. The four serious errors included two tenfold dose miscalculations. Most $(71 \%)$ of the errors were due to poor prescribing. After the introduction of our interventions, monthly medication errors fell from a mean (SD) of 24.1 (1.7) per 1000 neonatal activity days to 5.1 (3.6) per 1000 days $(p<0.001)$ in the following three months. The subsequent change over of junior medical staff was associated with a significant increase in medication errors to 12.2 (3.6) per 1000 neonatal activity days ( $p=0.037$ ). However, the number remained significantly less than before our interventions $(p<0.001)$. Three serious errors occurred in the first four months compared with one in the second eight month period, the latter corresponding to the six monthly change over of junior medical staff.

Conclusions: Medication errors are common in NICUs. Fortunately, actual harm to an infant is rare. Interventions to reduce errors, particularly within the context of a risk management programme, are effective.
M edication errors are an avoidable cause of iatrogenic injury in paediatric patients. ${ }^{1}$ Theories of human error provide insight into the reasons for medication errors, and have identified specific risk factors including workload, lack of knowledge, inadequate training, and absence of awareness of errors. ${ }^{2}$

Prevention of medication errors is a government priority as well as a clinical necessity. ${ }^{3}$ Strategies to reduce errors have included increased input from clinical pharmacists, ${ }^{4-6}$ system change implemented by critical incident analysis, ${ }^{7}$ and, most recently, the use of information technology. ${ }^{89}$ The neonatal intensive care unit (NICU) is recognised to be a particularly high risk environment for the occurrence of medication errors, ${ }^{10}{ }^{11}$ but there are very few data on the effect of such interventions in an NICU.

In this prospective review, we describe the medication errors occurring in our unit, and assess the impact of a combined risk management/ward based, clinical pharmacist led education programme on these errors.

\section{METHODS}

From January 2002 until January 2003, medication errors were prospectively reviewed in a large, tertiary referral NICU. Errors were identified using critical incident reporting forms. Forms were completed either by nursing or medical staff involved in the error or by the clinical pharmacist. The pharmacist reviewed all medication orders in the NICU for legality (adherence to the Greater Glasgow Health Board Prescribing Policy) and accuracy (adherence to the neonatal unit formulary). Critical incident forms were analysed monthly in a non-punitive manner by a multidisciplinary risk management group consisting of a clinical pharmacist, a consultant neonatologist, a neonatal specialist registrar, and a senior nurse. Medication errors were graded as serious (actual harm or very high risk of harm to the infant), potentially serious (potential harm to the infant), or minor. After four months, a daily, cot side, pharmacist led review of medication orders and parenteral fluid prescriptions for each intensive care infant was introduced. The pharmacist was accompanied by the senior house officer and specialist registrar on-call for the unit. Issues relating to prescribing, documentation, and administration were discussed. The pharmacist remained easily contactable throughout the working day and out of hours if further discussion was required. Each new member of pharmacy, nursing, or medical staff was required to successfully complete a series of dose calculations, with additional help given by the pharmacist until competency was achieved. A regular newsletter describing medication errors in the unit was circulated to all staff. The impact of these interventions on subsequent medication errors was continuously monitored.

Before and throughout the study period, new medical staff received verbal and written instruction on good prescribing practice. This included avoidance of decimal points, writing units in full, and printing prescriptions. In addition, a comprehensive neonatal unit formulary was widely available as a hard copy and on the hospital intranet. Training was provided for all nursing staff involved in intravenous drug administration. It was unit policy that two people checked all medicines before administration.

During the one year period under review, several changes in practice were instituted based on our analysis of previous 
Table 1 Parenteral medicines involved in errors

\begin{tabular}{ll}
\hline Drug involved & $\mathbf{N}(\%)$ \\
\hline Gentamicin/netilmicin & $21(33)$ \\
Benzyl penicillin & $10(16)$ \\
Vancomycin & $9(14)$ \\
Morphine & $6(10)$ \\
Insulin & $4(6)$ \\
Aminophylline & $3(5)$ \\
Immunisations & $3(5)$ \\
Tazocin & $2(3)$ \\
Other & $5(8)$ \\
\hline
\end{tabular}

medication errors. Some of these changes coincided with the introduction of the pharmacist led review of medication orders-for example, the abolition of prescription writing during ward rounds-and others were introduced after this. These changes included writing the day as well as the date for medicines prescribed at unusual intervals (for example, gentamicin), provision of a single concentration of morphine for reconstitution on the NICU, and, where possible, reconstitution of intravenous medicines in the pharmacy. Insulin and heparin were stored in separate fridges to avoid confusion during reconstitution, and dedicated infusion pumps, preset for heparin, were used only for arterial line infusions.

Throughout the study period, monthly neonatal activity days were monitored.

\section{Statistical analysis}

Mean (SD) medication errors per 1000 neonatal activity days were calculated. These were compared using Student's $t$ test. Statistical significance was taken at $\mathrm{p}<0.05$.

\section{RESULTS}

A total of 105 errors were identified, four serious, 45 potentially serious, and 56 minor. Most (75\%) were reported by the clinical pharmacist, but all four serious errors were reported by medical or nursing staff involved in the error. Parenteral medicines were involved in 63 errors $(60 \%)$, oral medicines in 41 errors (39\%), and topical medicines in one error. Table 1 lists the parenteral medicines involved.

The four serious errors included two involving 10 -fold dose miscalculations. In one case, an infant who received an opiate overdose required naloxone, and in the second an antibiotic overdose was given which required no specific

\begin{tabular}{|c|c|c|c|c|}
\hline Month & $\begin{array}{l}\text { Intensive } \\
\text { care activity } \\
\text { (days) }\end{array}$ & $\begin{array}{l}\text { Special } \\
\text { care activity } \\
\text { (days) }\end{array}$ & $\begin{array}{l}\text { Total } \\
\text { activity } \\
\text { (days) }\end{array}$ & $\begin{array}{l}\text { Medication errors } \\
\text { per } 1000 \text { neonatal } \\
\text { activity days }\end{array}$ \\
\hline January & 236 & 398 & 634 & 23.7 \\
\hline \multicolumn{5}{|c|}{ New junior medical staff started } \\
\hline February & 234 & 435 & 669 & 23.9 \\
\hline March & 190 & 528 & 718 & 26.5 \\
\hline April & 223 & 359 & 582 & 22.3 \\
\hline \multicolumn{5}{|c|}{ Interventions started } \\
\hline May & 278 & 283 & 561 & 8.9 \\
\hline June & 205 & 419 & 624 & 4.8 \\
\hline July & 189 & 428 & 617 & 1.6 \\
\hline \multicolumn{5}{|c|}{ New junior medical staff started } \\
\hline August & 197 & 391 & 588 & 13.6 \\
\hline September & 159 & 391 & 508 & 17.7 \\
\hline October & 230 & 316 & 546 & 11.0 \\
\hline November & 190 & 383 & 573 & 8.7 \\
\hline December & 137 & 375 & 512 & 9.8 \\
\hline
\end{tabular}

treatment. The third serious error involved administration of an antibiotic to the wrong baby. There was no direct harm to the infant. The final serious error was a "near miss" situation involving the use of insulin rather than heparin to reconstitute a bag of "heparinised" saline. This error was identified before administration by a second member of staff checking the vial used for reconstitution.

Most $(71 \%)$ of the medication errors were due to poor prescribing. The most common example of this was an incorrect dose (unexplained deviation of $>10 \%$ from the neonatal unit formulary), which occurred in 37 cases. An incorrect dose interval was found in 19 errors; this was particularly common with gentamicin. Other examples of poor prescribing included incomplete prescriptions (14) and incorrect units (5). Thirty errors (29\%) were due to administration problems. In 16 cases, the medication was not documented as given, reflecting either poor communication between staff or more often poor documentation of administration. In eight errors, the medication was given incorrectly, either by the wrong route or too quickly, and in six cases administration was delayed by more than two hours, generally reflecting the intensity of work in the unit.

Following the introduction of our interventions after four months, medication errors fell from 24.1 (1.7) per 1000 neonatal activity days to 5.1 (3.6) per 1000 days ( $p<0.001$ ) in the following three months (table 2). The change over of junior medical staff in August was associated with a significant increase in medication errors to 12.2 (3.6) per 1000 neonatal activity days $(\mathrm{p}=0.037)$. However, the number remained significantly less than before our interventions $(p<0.001$; table 2 ). Three serious errors occurred in the first four months compared with one in the second eight month period, the latter corresponding to the six monthly change over of junior medical staff.

\section{DISCUSSION}

In common with other authors, ${ }^{11}$ we found that medication errors occur regularly in our NICU. Fortunately, actual harm to an infant is rare. The types of drugs used, many of which have a narrow therapeutic margin, and the ease of miscalculation during reconstitution from stock solutions based on adult concentrations mean that the potential for harm from these errors is great. ${ }^{12} 13$

We have shown that interventions to improve staff education and awareness of errors are effective in reducing such errors, although within the context of our overall risk management approach, it is difficult to quantify the proportion of errors reduced by any one change in practice.

Inexperience is a particular risk factor for medication errors. ${ }^{2}$ This is supported by our own findings and those of others that new staff are more likely to make errors. ${ }^{14}$ This is compounded by the fact that prescriptions are often written by the most junior doctors who may be unfamiliar with the medicine. ${ }^{2}$ The importance of the paediatric clinical pharmacist in monitoring drug treatment and preventing medication errors is well established. ${ }^{45}$ Fortescue et al ${ }^{15}$ recently showed that clinical pharmacist monitoring of orders might prevent $58 \%$ of all errors and $72 \%$ of potentially harmful errors, and that improved doctor-pharmacist communication might prevent $47.4 \%$ of errors. ${ }^{15}$ We found that close liaison with a ward based clinical pharmacist is an effective way of reducing errors. We effectively extended the role of the pharmacist to include real time staff feedback and education, both informally while reviewing medication orders and formally as a series of dose calculations. Calculation errors, particularly 10-fold errors, can be potentially fatal and any intervention to reduce these is important. ${ }^{12}$

Intensity of workload is recognised to be another risk factor for medication errors. ${ }^{2}$ We used neonatal activity days 
as a surrogate marker of workload to correct for the potential confounding effect of variations in activity. We accept, however, that a description of medication errors per number of prescriptions written would provide more accurate information on the impact of workload.

Longitudinal monitoring enabled us to identify sources of recurrent error and facilitate several changes in our practice. This technique of continuous critical incident monitoring and quality improvement through system change has been described previously in an NICU. ${ }^{7}$ In this prospective study of 284 medication related critical incidents, 46 were followed by system changes. ${ }^{7}$ Knowledge acquired in this way, even from apparently minor errors, is an important resource in the prevention of future errors.

Prescribers are human and therefore mistakes will be made. Recognition of these errors is the first step in their prevention. It is important that prescribers are aware of their own vulnerability and that we all learn from our own mistakes and those of others. Increased awareness of error is an important preventive tool. In addition, we feel that ward based input from a clinical pharmacist, particularly within the context of a risk management programme, is important in the NICU both to monitor medication orders and to provide education to frequently changing members of staff.

\section{Authors' affiliations}

J H Simpson, R Lynch, J Grant, L Alroomi, Paediatric Department, Princess Royal Maternity Hospital, Glasgow G31 2ER, Scotland, UK

\section{REFERENCES}

1 Ross LM, Wallace J, Paton JY. Medication errors in a paediatric teaching hospital in the UK: five years operational experience. Arch Dis Child 2000;83:492-7.

2 Dean B, Schachter M, Vincent C, et al. Causes of prescribing errors in hospital inpatients: a prospective study. Lancet 2002;359:1373-8.

3 Expert Group on Learning from Adverse Events in the NHS. An organisation with a memory. London: Department of Health, 2000.

4 Folli $\mathrm{HL}$, Poole RL, Benitz WE, et al. Medication error prevention by clinical pharmacists in two children's hospitals. Pediatrics 1987;79:718-22.

5 Koren G, Reich A, Hales B. The role of clinical pharmacists in preventing potentially fatal ten-fold medication errors in children. J Pharm Technol 1991;7:219-21.

6 Leape LL, Cullen DJ, Clapp MD, et al. Pharmacist participation on physician rounds and adverse drug events in the intensive care unit. JAMA 1999;282:267-70.

7 Frey B, Buettiker V, Hug Ml, et al. Does critical incident reporting contribute to medication error prevention? Eur J Pediatr 2002;161:594-9.

8 Kaushal R, Shonjania KG, Bates DW. Effects of computerized physician order entry and clinician decision support systems on medication safety: a systematic review. Arch Intern Med 2003;163:1409-16.

9 King JW, Paice N, Rangrej J, et al. The effect of computerized physician order entry on medication errors and adverse drug events in pediatric inpatients. Pediatrics 2003; 112:506-9.

10 Kaushal R, Barker KN, Landrigan C, et al. Medication errors and adverse drug events in pediatric inpatients. JAMA 2001;285:2114-20.

11 Deshpande SA. How common are violations of good prescribing practice in the neonatal unit? Arch Dis Child 2003;88(suppl 1):A20.

12 Koren G, Barzilay Z, Greenwald M. Tenfold errors in administration of drug doses: a neglected iatrogenic disease in pediatrics. Pediatrics 1986;77:848-9.

13 Choonara I. How to harm children in hospital: a guide for junior doctors. Paediatric and Perinatal Drug Therapy 1999;3:34-5.

14 Wilson DG, McArtney RG, Newcombe RG, et al. Medication errors in paediatric practice: insights from a continuous quality improvement approach. Eur J Pediatr 1998;157:769-74.

15 Fortescue EB, Kaushal R, Landrigan CP, et al. Prioritizing strategies for preventing medication errors and adverse drug events in pediatric inpatients. Pediatrics 2003;111:722-9. 